\title{
A Simple Green Synthesis of Palladium Nanoparticles with Sargassum Alga and Their Electrocatalytic Activities Towards Hydrogen Peroxide
}

\author{
S. Momeni ${ }^{1} \cdot$ I. Nabipour $^{1}$
}

Received: 28 March 2015 / Accepted: 25 May 2015 /

Published online: 4 June 2015

(C) Springer Science+Business Media New York 2015

\begin{abstract}
This study presents the synthesis of palladium nanoparticles (PdNPs) using the extract derived from the marine alga, Sargassum bovinum, collected from Persian Gulf area. Water-soluble compounds that exist in the marine alga extract were the main cause of the reduction of palladium ions to Pd nanoparticles. The basic properties of PdNPs produced in this method were confirmed by UV-visible spectroscopy, transmission electron microscopy (TEM), X-ray diffraction (XRD), energy-dispersive X-ray (EDX) analysis, and Fourier transform infrared spectroscopy (FTIR). TEM confirmed the monodispersed and octahedral shape of PdNPs within the size ranges from 5 to $10 \mathrm{~nm}$. Catalytic performance of the biosynthetic PdNPs was investigated by electrochemical reduction of hydrogen peroxide $\left(\mathrm{H}_{2} \mathrm{O}_{2}\right)$. PdNPmodified carbon ionic liquid electrode (PdNPs/CILE) was developed as a nonenzymatic sensor for the determination of hydrogen peroxide. Amperometric measurements showed that $\mathrm{PdNPs} / \mathrm{CILE}$ is a reliable sensor for the detection of hydrogen peroxide in the range of $5.0 \mu \mathrm{M}-15.0 \mathrm{mM}$ with a sensitivity of $284.35 \mathrm{mAmM}^{-1} \mathrm{~cm}^{-2}$ and a detection limit of $1.0 \mu \mathrm{M}$. Moreover, PdNPs/CILE exhibits a wide linear range, high sensitivity and selectivity, and excellent stability for the detection of $\mathrm{H}_{2} \mathrm{O}_{2}$ in aqueous solutions.
\end{abstract}

Keywords Alga Carbon ionic liquid electrode $\cdot$ Hydrogen peroxide $\cdot$ Palladium nanoparticles Sargassum

\section{Introduction}

Nanomaterials are different from bulk structures due to their small size and large surface to volume ratio and offer unusual chemical, optical, photoelectrochemical, and electronic

S. Momeni

safieh.momeni@gmail.com

1 Persian Gulf Marine Biotechnology Research Center, The Persian Gulf Biomedical Sciences Research Institute, Bushehr University of Medical Sciences, Bushehr 75147, Iran 
properties. Among various metallic nanoparticles, palladium nanoparticles (PdNPs) are widely investigated due to their wide applications in sensors, biosensors, and catalysts. PdNPs have been studied as catalysts for a range of reactions such as the catalytic hydrogenation [1], Suzuki-Miyaura and Mizoroki-Heck cross-coupling reactions [2], and decolorization of azo dyes [3]. In addition to this, owing to the good electrocatalytic activity of PdNPs, they have also been used as the electrocatalyst in fuel cells and biosensors. PdNPs were employed for detection of $\mathrm{O}_{2}$ [4], formaldehyde [5], hydrogen peroxide [6-10], and hydrazine [11]. Due to the wide-ranging applications of PdNPs, production of nanoparticles through environmentfriendly methods has a significant role in meeting the increasing demand for nanomaterials.

Metal nanoparticles are often synthesized through chemical and physical methods [12], electrochemical techniques [13], and nowadays via biological methods [14]. Chemical and physical approaches are quite expensive and often produce toxic materials which are potentially harmful to the environment. Synthesis of nanoparticles through biological methods provides an alternative to chemical and physical methods as it is environment friendly, cost-effective, and does not require the use of high pressure, temperature, energy, and toxic chemicals. In the biological method, extracts from living organisms may act both as reducing and stabilizing agents in the synthesis of nanoparticles [15]. The biomolecules found in these extracts such as enzymes/ proteins, polysaccharides, amino acids, and polyphenols were reduced metal ions and produced nanoparticles. The exact mechanism of nanoparticle synthesis by using biological extracts is yet to be understood.

Marine organisms such as bacteria, cyanobacteria, fungi, and algae are reported to synthesize nanoparticles such as gold, silver, calcium, silicon, iron, and lead either inside or outside cells [16]. Additionally, marine animals such as finfish and sponges are also capable of synthesizing the nanoparticles [17]. Biosynthesis of nanoparticles by using marine organisms can be performed by several compounds such as carbonyl groups, terpenoids, phenolics, flavonones, polysaccharides, proteins, pigments, amines, amides, alkaloids, and other reducing agents existent in the biological extracts. Biosynthesis of nanoparticles by various marine organisms has been extensively reviewed [16].

Sargassum, a genus of brown seaweed, is found in all oceans and involves approximately 400 species [18]. About 200 bioactive compounds, such as meroterpenoids, phlorotanins, fucoidans, sterols, and glycolipids, have been identified to be derived from this genus. The biological effects of new metabolites from Sargassum alga have been reviewed recently [19]. The brown seaweeds such as Sargassum wightii [20] and Fucus vesiculosus [21] and red seaweeds such as Gracilaria sp [22] and Gelidiella acerosa [23] are capable of synthesizing gold and silver nanoparticles. In addition to seaweeds, microalgae such as diatoms [24] (Navicula atomus, Diadesmis gallica) have the ability to synthesize gold nanoparticles.

There are several reports in literature describing the reduction of palladium ions by green methods [25-27]. The bioreduction of palladium ions by the extract of Cinnamomum camphora leaf led to the formation of palladium nanoparticles. Moreover, the size of PdNPs could be easily controlled by variation of the initial concentration of Pd (II) ions [25]. Reduction of palladium ions to nanoscale palladium particles using an extract of plant material, C. zeylanicum bark, was investigated by M. Sathishkumar et al. [26]. Gardenia jasminoides Ellis' water crude extract was used for the bioreduction of palladium chloride and demonstrated that antioxidants including geniposide, chlorogenic acid, crocins, and crocetin were reducing and stabilizing agents for synthesizing PdNPs in water crude extract [27]. A review 
of the relevant literature revealed that synthesis of PdNPs using algae has not been investigated so far, which aroused our interest in the present study. Therefore, this study attempts to assess the possibility of the production of palladium nanoparticles through a crude extract of Sargassum alga. The green synthesis of PdNPs using crude extract from Sargassum alga would provide an alternative to the chemical method.

Hydrogen peroxide $\left(\mathrm{H}_{2} \mathrm{O}_{2}\right)$ is one of the most important substances playing the role of a mediator in the food, pharmaceutical, medical, and chemical industries [28]. $\mathrm{H}_{2} \mathrm{O}_{2}$ is also a major by-product of many biological reactions catalyzed by various enzymes [29]. Thus, rapid and reliable determination of $\mathrm{H}_{2} \mathrm{O}_{2}$ is of great importance.

Electrochemical sensors have been applied as promising tools for the detection of $\mathrm{H}_{2} \mathrm{O}_{2}$ due to their low cost, high selectivity and sensitivity, fast response, and simplicity [30-33]. The electrochemical sensors are usually based upon the surface modification of electrodes with enzymes or proteins such as horseradish peroxidase [34], hemoglobin [35], or myoglobin [36]. The presence of enzymes or proteins on the surface of electrode accelerates the transfer of the electron between the electrodes and $\mathrm{H}_{2} \mathrm{O}_{2}$. However, enzyme-modified electrodes often show low stability and require complex immobilization procedures and critical operation conditions. In nonenzymatic $\mathrm{H}_{2} \mathrm{O}_{2}$ sensors, the appropriate modification of electrode surface has generally been performed to enhance the electron transfer between the electrode and $\mathrm{H}_{2} \mathrm{O}_{2}$ as well as to minimize the overpotential. Nanomaterials have provided new opportunities for the evolution of novel nonenzymatic $\mathrm{H}_{2} \mathrm{O}_{2}$ sensors [37]. Among the various nanomaterials, noble metal nanoparticles have also attracted extensive attentions for their applications in many features including catalysis and biosensoring.

In this report, we investigated the biological, natural, and low-cost crude extract of marine Sargasssum alga as a reducing and capping agent for the synthesis of PdNPs. Thus, the use of hazardous chemicals and solvents was eliminated. This method of nanoparticle preparation has great importance for the future likely applications due to its simplicity, accessibility, and effectiveness. Furthermore, the as-prepared Pd nanoparticle-modified carbon ionic liquid electrode (PdNPs/CILE) was employed for the determination of $\mathrm{H}_{2} \mathrm{O}_{2}$ via electrochemical reduction by using cyclic voltammetric $(\mathrm{CV})$ and amperometric methods. CILE and nanoparticles modified by CILE have been known to be a very suitable electrode for the oxidation or reduction of a wide range of analytes [38, 39]. The results showed that the PdNPs/CILE has high sensitivity and selectivity, wide linear range, and good stability for the determination of $\mathrm{H}_{2} \mathrm{O}_{2}$ in aqueous solutions. The interesting performances of the electrode coupled with its simple and green preparation procedure of PdNP synthesis make it a promising electrochemical sensing platform.

\section{Experimental}

\section{Chemicals and Reagents}

Palladium chloride $\left(\mathrm{PdCl}_{2}\right)$, ascorbic acid (AA), uric acid (UA), ethanol, 1-iodooctane, pyridine, and diethyl ether were purchased from Merck. Hydrogen peroxide $\left(\mathrm{H}_{2} \mathrm{O}_{2}\right)$ and dopamine (DA) were obtained from Sigma. Ammonium hexafluorophosphate and graphite powder (mesh size $<100 \mathrm{~lm}$ ) were supplied from Fluka. Double-distilled water was used throughout the experiment. 


\section{Apparatus}

The electrochemical measurements were carried out using an Autolab Electrochemical System (Eco-Chemie, Utrecht, The Netherlands) equipped with Autolab type II and GPES software (Eco-Chemie) in a classical three-electrode cell equipped with CILE and PdNPs/CILE (1.8 $\mathrm{mm}$ in diameter), platinum plate, and $\mathrm{Ag} / \mathrm{AgCl}$ as the working, counter, and reference electrode, respectively. Electrocatalytic properties for $\mathrm{H}_{2} \mathrm{O}_{2}$ reduction were investigated in a $0.1 \mathrm{M}$ phosphate buffer solution ( $\mathrm{PBS}, \mathrm{pH} 7$ ) at room temperature. The phosphate buffer solutions were made by sodium phosphates $\left(\mathrm{Na}_{2} \mathrm{HPO}_{4}, \mathrm{NaH}_{2} \mathrm{PO}_{4}\right)$. All the test solutions were thoroughly deoxygenated by pure nitrogen for about 10 min prior to each experiment. FTIR analyses were recorded using Shimadzu FTIR-8300 series in the range of 4000 to $400 \mathrm{~cm}^{-1}$. The morphology and size of PdNPs were visualized using Transmission Electron Spectroscopy (TEM) on a Zeiss-EM10C-80 KV. XRD measurements were carried out on a D8, Avance, Bruker, AXS diffractometer with $\mathrm{Cu}-\mathrm{K} \alpha$ radiation $(\lambda=1.5418 \AA$ ) with a scan speed of $2 \% \mathrm{~min}$. Absorption spectrum was recorded on a Specord Analytic Jena UV-visible spectrophotometer.

\section{Preparation of the Extracts}

Sargassum bovinum alga were collected along the Bushehr coast of the Persian Gulf (Southwestern Iran) in May 2014. The alga was brought to the laboratory and cleaned thoroughly in fresh water and then by distilled water to remove sand and salts. After cleaning, algae were dried in shade at room temperature for 1 week. The dried sample was ground to powder in a mortar. Briefly, about $1 \mathrm{~g}$ of dry alga material was homogenized in $100 \mathrm{ml}$ double-distilled water and boiled for $15 \mathrm{~min}$. The crude extract was passed through a Whatman No.1 filter paper and the filtrates were stored at $4{ }^{\circ} \mathrm{C}$ for further use.

\section{Synthesis of Pd Nanoparticles}

For the synthesis of $\mathrm{Pd}$ nanoparticles, about $50 \mathrm{~mL}$ aqueous solution of $1 \mathrm{mM}$ palladium chloride $\left(\mathrm{PdCl}_{2}\right)$ was mixed with $10 \mathrm{~mL}$ of crude extract of marine alga. The whole mixture was put into a rotary shaker at $60{ }^{\circ} \mathrm{C}(160 \mathrm{rpm})$ for $24 \mathrm{~h}$ and maintained in the dark. Control experiments were conducted by inoculated media, to check for the role of alga in the synthesis of nanoparticles. The progress of the reaction was monitored by observing color changes as well as recording UV-visible spectrum. The initial yellow solution turned to dark brown, indicating the formation of palladium nanoparticles. For the characterization and application of Pd nanoparticles, the dark brown color solution was centrifuged at $12,000 \times g$ for $30 \mathrm{~min}$ using a high-speed centrifuge (Eppendorf centrifuge 5810R). The pellet obtained was washed with distilled water and ethanol and centrifuged again for $30 \mathrm{~min}$. The process was repeated to remove water-soluble biomolecules from PdNP suspension. These nanoparticles were found free of any contamination and were suitable for FTIR, TEM, XRD, and other analyses.

\section{Electrode Preparation}

A PdNPs/CILE electrode was constructed by hand mixing the weighed amounts of graphite powder, ionic liquid $\left(\mathrm{OPyPF}_{6}\right)$, and PdNPs $(50 \%: 40 \%: 10 \%$, wt \%), respectively. These substances were mixed to yield a paste. A portion of the resulting paste was packed into the cavity (1.8 mm i.d.) of a Teflon holder. In order to have a lower background current and a 
better homogeneity of the composite, the electrode should be heated to a temperature above the melting point of the ionic liquid ( $\mathrm{mp} 65^{\circ} \mathrm{C}$ ) prior to its use [38]. The electric contact was established via a copper wire. A new surface of the electrode was obtained easily by polishing the electrode surface by a smooth paper.

\section{Results and Discussion}

A detailed study on the marine alga biosynthesis of palladium nanoparticles was performed in this work. The appearance of dark brown color in the reaction mixture indicates the synthesis of palladium nanoparticles form crude extract of Sargassum alga with $1 \mathrm{mM}$ palladium chloride solution. PdNPs were accessed via bioreduction of aqueous palladium solution with dried biomass of a brown alga, S. bovinum. The conversion of palladium ions into metallic palladium was monitored by UV-Vis absorption measurement in the range of 300-800 nm. UV-visible spectra of the synthesized PdNPs were showed in Fig. 1. The inset of Fig. 1 shows the change in solution color (from yellow to dark brown). Figure 1 displays the absorption spectra of palladium nanoparticles after $24 \mathrm{~h}$ of bioreduction by the crude extract of Sargassum alga and the absorption spectra of $\mathrm{PdCl}_{2}$ solution, used for comparison. The absorption bands observed in the spectrum of $\mathrm{PdCl}_{2}$ solution were attributed to the ligand-to-metal chargetransfer transition of the Pd (II) ions [40]. The absence of the absorption peaks above $300 \mathrm{~nm}$ in the spectrum of Pd nanoparticles confirmed the complete reduction of the initial Pd (II) ions. The spectra of the PdNPs showed a broad absorption band extending throughout the visiblenear-ultraviolet region, which was attributed to the PdNPs. In order to confirm the reduction of palladium ions by chemical constituents of the medium, a parallel experiment without the crude extract of algal was also carried out. The synthesized nanoparticles covered with biomolecules are well dispersed in the solution and fairly stable up to 5 months.

The obtained result from the TEM study provides clear evidence regarding the shape and size of the nanoparticles. The PdNPs synthesized by the aid of Sargassum extract were scanned using TEM from which the average mean size of the PdNPs was $5 \mathrm{~nm}$ and seemed to be octahedral [41] in morphology as shown in Fig. 2a. EDX spectra reveal strong signals in

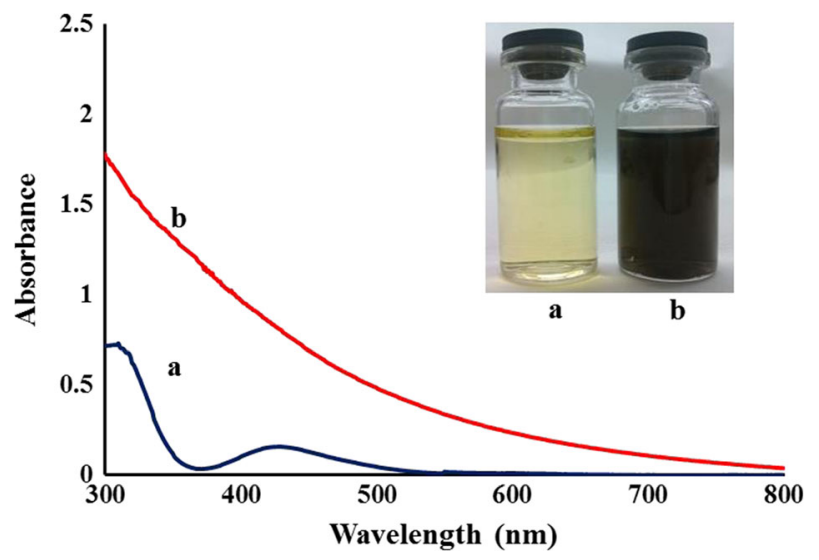

Fig. 1 UV-visible spectra of $\mathbf{a} \mathrm{PdCl}_{2}$ solution and $\mathbf{b}$ PdNPs after bioreduction by crude extract of marine alga at $60{ }^{\circ} \mathrm{C}$ for $24 \mathrm{~h}$. The inset shows an image of the as-prepared $\mathrm{Pd}$ colloidal solution and the $\mathrm{PdCl}_{2}$ solution before reaction 
the palladium region and confirm the formation of $\mathrm{Pd}$ nanoparticles and its elemental nature (Fig. 2b).

Further studies were carried out using X-ray diffraction to confirm the crystalline nature of the nanoparticle, and the XRD pattern obtained was represented in Fig. 3. XRD analysis showed three distinct diffraction high-intensity peaks at $40.0^{\circ}, 46.5^{\circ}$, and $68.0^{\circ}$, which indexed the planes (111), (200), and (220) of the cubic face centered Pd followed by a couple of peaks at $81.9^{\circ}$ and $86.4^{\circ}$ indexed the 311 and 222 planes [41]. This clearly proves that the $\mathrm{Pd}$ nanoparticles formed in the green synthesis are crystalline in nature.

FTIR measurements were carried out to identify the possible biomolecules responsible for the reduction of the Pd ions and capping of the bioreduced PdNPs synthesized by the crude extract. The FTIR spectra of the crude extract of marine alga and biosynthesized PdNPs are depicted in Fig. 4. FTIR spectrum of the crude extract of alga shows peaks at 3391, 3317, $2938,1623,1458,1388,1321,1263,1198,1085,1020,953,927,884,722$, and $630 \mathrm{~cm}^{-1}$ in the region of 400-4000 $\mathrm{cm}^{-1}$. The curve of the crude extract of alga shows a strong band at $3391 \mathrm{~cm}^{-1}$ corresponding to the $\mathrm{O}-\mathrm{H}$ broad stretch of high concentration of alcohols or phenols. After the reduction of Pd ions, the decrease of intensity at $3319 \mathrm{~cm}^{-1}$ implies the involvement of the $\mathrm{OH}$ groups in the reduction process. Therein, the absorbance bands at 1020,1085 , and $1198 \mathrm{~cm}^{-1}$ in curve a of Fig. 4 could be assigned to the stretch vibration of C$\mathrm{O}$, and a band at $1623 \mathrm{~cm}^{-1}$ might result from conjugated $\mathrm{C}=\mathrm{O}$ group. The band at $2938 \mathrm{~cm}^{-1}$ arose due to $\mathrm{C}-\mathrm{H}$ stretching, and those at $800-450 \mathrm{~cm}^{-1}$ could be assigned to the aromatic groups. The peaks at $1458 \mathrm{~cm}^{-1}$ indicate the $\mathrm{C}-\mathrm{C}$ groups derived from aromatic rings that exist in the crude extract. FTIR spectrum of Pd nanoparticles biosynthesized by alga extract of marine alga shows peaks at $3401,2917,1607,1375,1235$, and $1040 \mathrm{~cm}^{-1}$. These peaks generally occur in polysaccharide spectrum indicating the participation of sulfated polysaccharides in the synthesis of PdNPs [42]. Thus, the result revealed that the capping of the PdNPs has mostly been carried out by sulphated polysaccharides existent in Sargassum alga.

A few algal species have shown the potential to synthesize nanoparticles by releasing biomolecules which can reduce ions to nanoparticles. Sargassum is rich in terpenoids, polyols, and polysaccharides which contribute to its distinct aroma. Shankar et al. reported that the polyols such as terpenoids, flavones, and polysaccharides in the marine alga were reported to

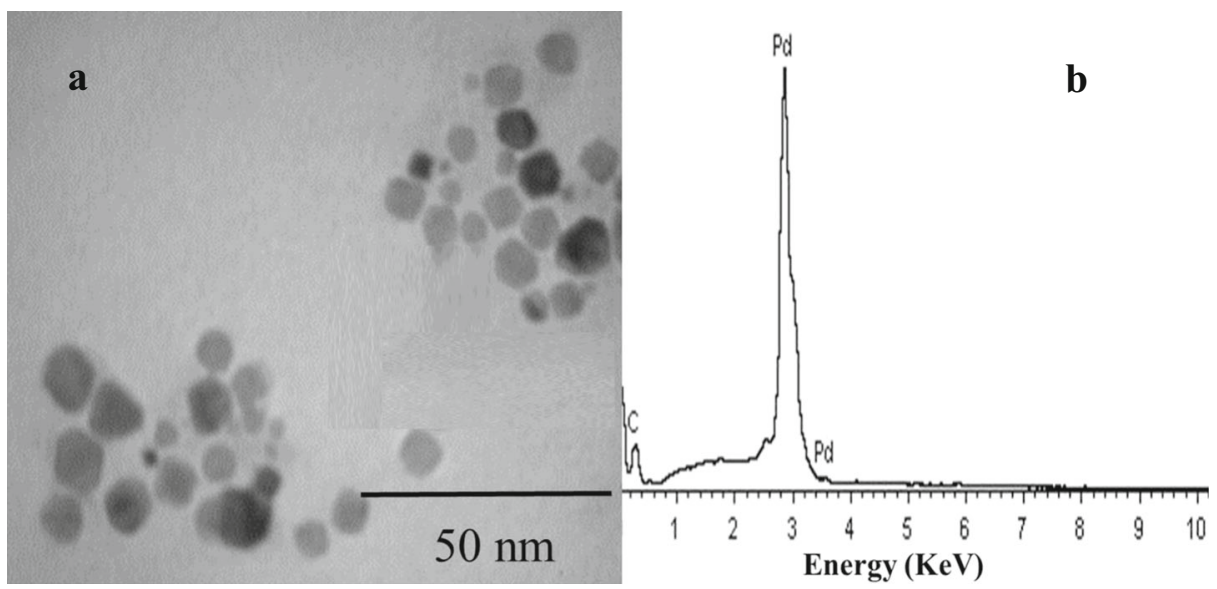

Fig. 2 TEM image a and EDX spectrum $\mathbf{b}$ of Pd nanoparticles after bioreduction. Ten milliliters of crude extract of alga reacted with $1 \mathrm{mM} \mathrm{PdCl}_{2}$ at $60{ }^{\circ} \mathrm{C}$ 


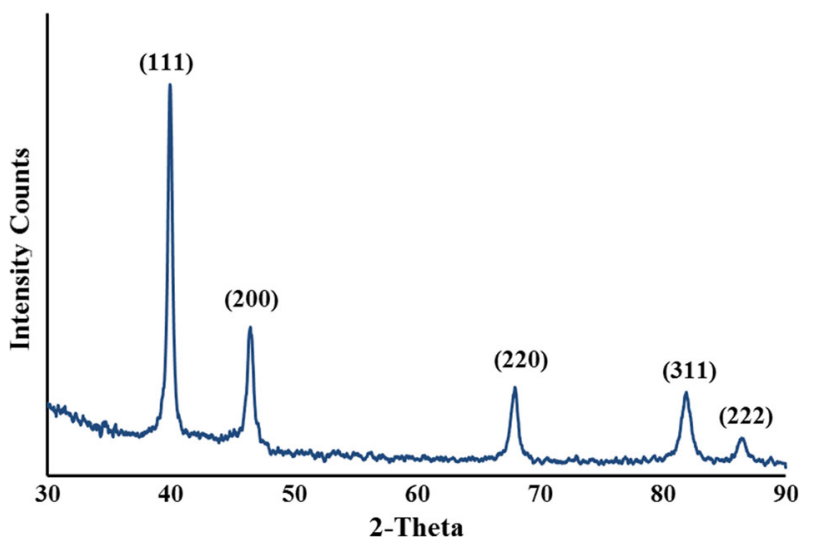

Fig. 3 XRD patterns of the as-prepared PdNPs. Labeled peaks correspond to the characteristic diffraction peaks of elemental $\operatorname{Pd}(0)$

be the main cause of the bioreduction of silver and chloroaurate ions [22]. Li et al. demonstrated that a reduction of palladium took place between the hydroxyl group of the polyols in the C. camphora leaf broth and the Pd (II) ions [25]. Likewise, the reaction between the crude extract of Sargassum alga and the Pd (II) species might occur based on the similar reaction, where the polyol and polysaccharides extracted from the Sargassum alga reduced and capped the PdNPs, thereby stabilizing them. However, it is not yet clear which compounds are responsible for the reduction and stabilization of the palladium nanoparticles.

The electrocatalytic activity of as-prepared Pd nanoparticle-modified CILE towards the reduction of $\mathrm{H}_{2} \mathrm{O}_{2}$ was investigated by cyclic voltammetry in $0.1 \mathrm{M}$ PBS. Figure 5 shows the

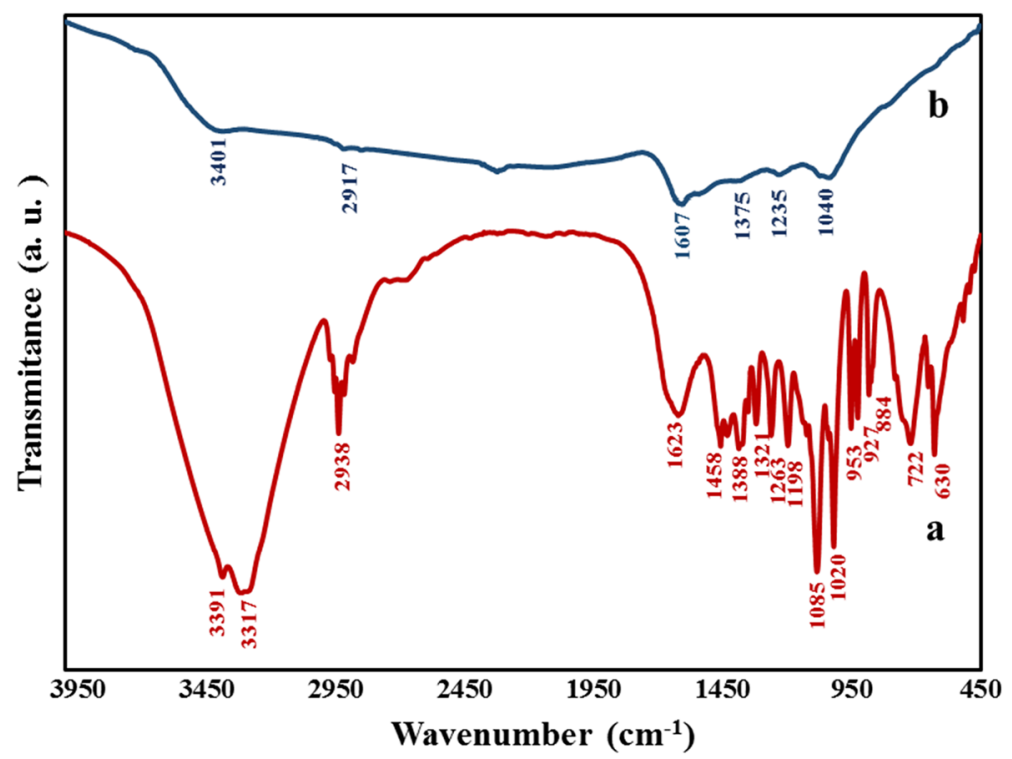

Fig. 4 Typical FTIR spectra of the alga biomass before bioreduction (a) and dried PdNPs after bioreduction of Pd ions (b) 
cyclic voltammograms of $1.0 \mathrm{mM} \mathrm{H} \mathrm{H}_{2}$ at (a) bare CILE and (b) PdNP-modified CILE (PdNPs/CILE). The bare CILE did not show any significant response to $1.0 \mathrm{mM} \mathrm{H}_{2} \mathrm{O}_{2}$ in the studied potential range. Contrastingly, a significant difference in peak potentials and peak currents can be observed at the $\mathrm{CV}$ curves of PdNPs/CILE in the presence of $\mathrm{H}_{2} \mathrm{O}_{2}$, indicating the promotion role of palladium nanoparticles towards $\mathrm{H}_{2} \mathrm{O}_{2}$ reduction. In the presence of $1.0 \mathrm{mM}$ of $\mathrm{H}_{2} \mathrm{O}_{2}$, a catalytic reduction peak with a relatively high current response can be observed around $-0.1 \mathrm{~V}$ at the surface of PdNPs/CILE, which is more positive than some previously reported potentials for $\mathrm{H}_{2} \mathrm{O}_{2}$ reduction.

The effect of the scan rate for PdNPs/CILE on the hydrogen peroxide reduction was investigated. It can be seen that the reduction current increases with increasing the scan rate. The peak current was linearly proportional to the square root of the scan rate within 5$500 \mathrm{mVs}^{-1}, I=-0.3205 v^{1 / 2}-1.445$, which indicates that hydrogen peroxide reduction is controlled by a diffusion process.

Electrocatalytic activity of the PdNPs/CILE electrode towards $\mathrm{H}_{2} \mathrm{O}_{2}$ reduction was further examined by amperometric technique at a potential step of $-0.2 \mathrm{~V}$ which is in the activation potential region of $\mathrm{H}_{2} \mathrm{O}_{2}$ reduction. The amperometric response of the PdNPs/CILE was measured by successive injection of $\mathrm{H}_{2} \mathrm{O}_{2}$ under a stirred condition (Fig. 6). As hydrogen peroxide was added to the PBS, the reduced current increased stepwise, and a well-defined amperometric response was obtained. Figure $6 \mathrm{~b}$ shows the enlargement of the lower section of the amperogram. Reduction reaction is very fast and the current reaches a steady-state level within 3-5 s upon successive additions of hydrogen peroxide. The inset of Fig. 6a demonstrates a linear calibration curve for $\mathrm{H}_{2} \mathrm{O}_{2}$ sensing at the PdNPs/CILE, indicating a broad dynamic measurement range from $5 \mu \mathrm{M}$ to $15 \mathrm{mM}$. The sensitivity determined by the slope of the calibration plot is $284.35 \mu \mathrm{A} \mathrm{mM} \mathrm{cm}^{-1}$. The limit of detection of $1 \mu \mathrm{M}$, based on a signal-to-noise ratio of 3 , was obtained experimentally. The wide linear range, good sensitivity, and low detection limit of this sensor can be due to the efficient electrocatalytic activity of $\mathrm{Pd}$ nanoparticles for $\mathrm{H}_{2} \mathrm{O}_{2}$ reduction.

The reproducibility of the PdNPs/CILE was investigated to evaluate its applicability. The relative standard deviation (RSD) for monitoring the response of five separate electrodes made with different CILE pastes to $1 \mathrm{mM} \mathrm{H}_{2} \mathrm{O}_{2}$ was calculated to be $3.2 \%$, and a single electrode

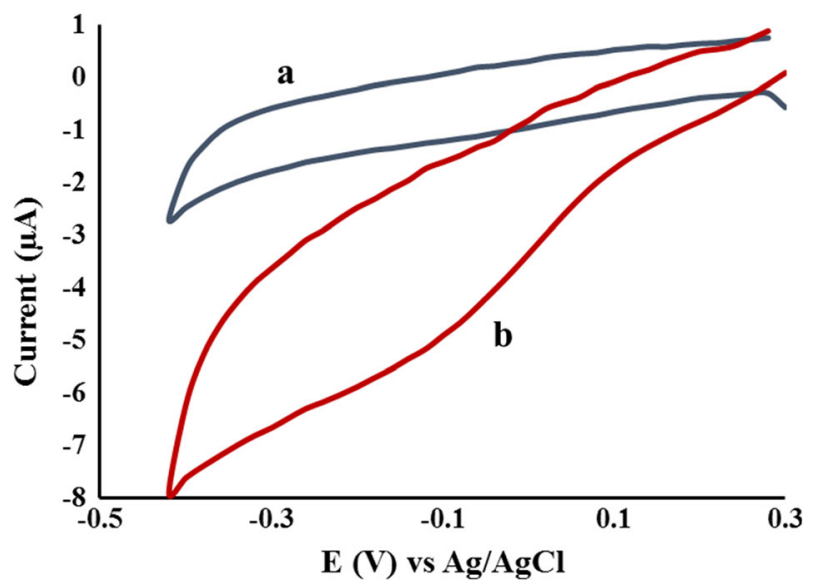

Fig. 5 Cyclic voltammograms of $1.0 \mathrm{mM}$ hydrogen peroxide reduction in $0.1 \mathrm{M}$ PBS (pH 7.0) at a bare CILE and $\mathbf{b}$ PdNP-modified CILE surface. Scan rate $50 \mathrm{mV} \mathrm{s}^{-1}$ 

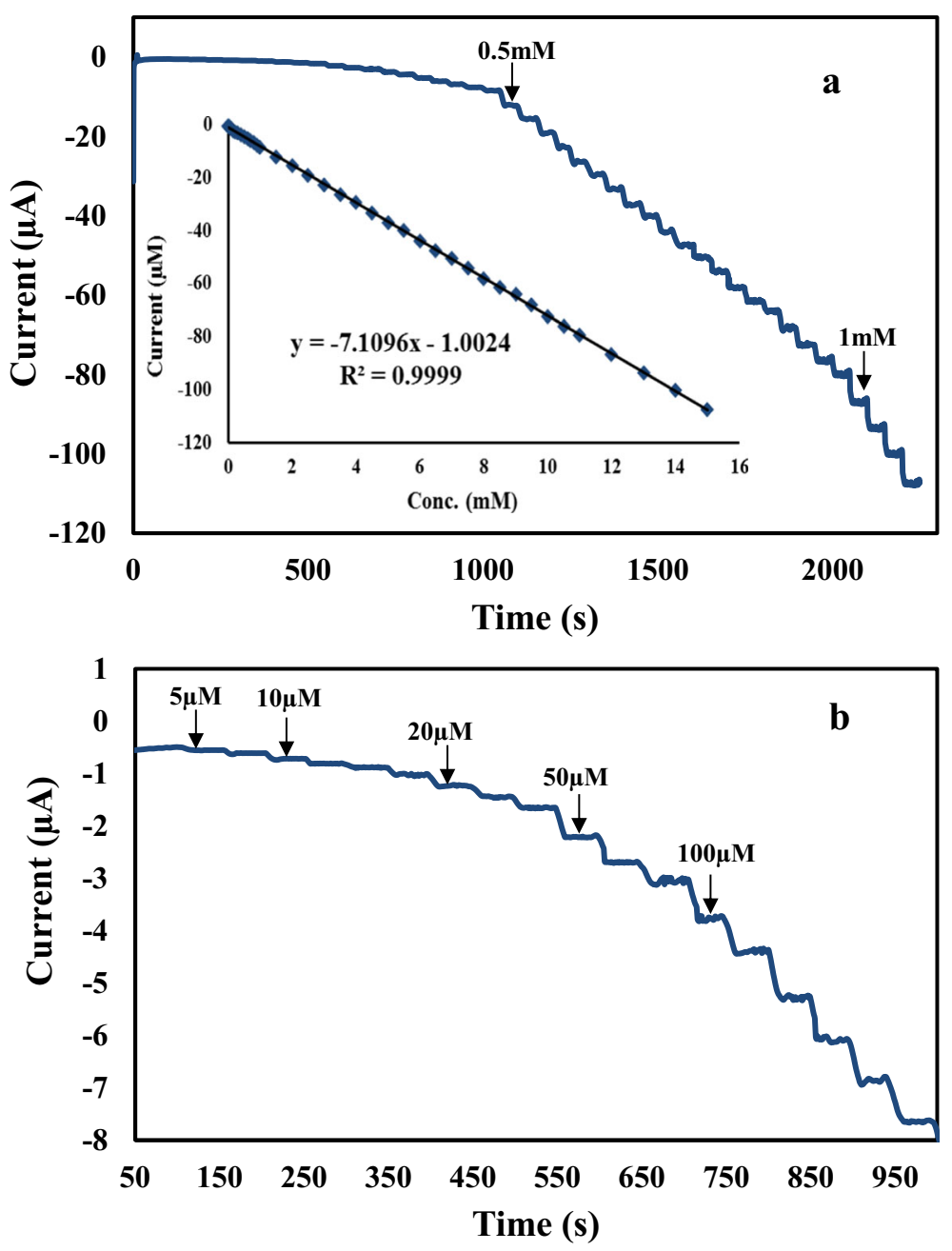

Fig. 6 a Amperometric response of the PdNP/CILE upon successive injection of $\mathrm{H}_{2} \mathrm{O}_{2}$ (indicated by arrows with marked concentrations) to $0.1 \mathrm{M} \mathrm{N}_{2}$-saturated PBS solution (pH 7.0) at $-0.2 \mathrm{~V}$. Inset-the corresponding calibration plot of steady-state currents against concentrations of $\mathrm{H}_{2} \mathrm{O}_{2}$. b The magnification of the first part of the amperogram

using five consecutive determinations showed average RSD of less than $2.5 \%$. These results demonstrate the reliability of this method. A comparison between previously reported palladium-modified electrodes for the determination of hydrogen peroxide is presented in Table 1. A comparison reveals that the reduction of hydrogen peroxide at PdNPs/CILE is achievable at a low overpotential and provides good superiority in terms of sensitivity and linear calibration range. Thus, PdNPs/CILE is a promising candidate for the development of effective hydrogen peroxide sensing.

The selectivity of PdNPs/CILE were evaluated by amperometry in the presence of glucose, ascorbic acid (AA), uric acid(UA), and dopamine (DA), which are the common interfering materials for the detection of $\mathrm{H}_{2} \mathrm{O}_{2}$. The amperometric responses for the successive addition of 
Table 1 Comparison of the electrocatalytic behavior of PdNPs/CILE for hydrogen peroxide reduction with some of the Pd reported electrodes

\begin{tabular}{|c|c|c|c|c|c|}
\hline Electrode & Linear range & $\begin{array}{l}\text { Sensitivity } \\
\left(\mu \mathrm{AmM} \mathrm{m}^{-1} \mathrm{~cm}^{-2}\right)\end{array}$ & LOD & $\begin{array}{l}\text { Potential } \\
\text { (V) }\end{array}$ & Ref \\
\hline $\mathrm{Pd} / \mathrm{MCV}$ & $0.1 \mu \mathrm{M}-6.1 \mathrm{mM}$ & $0.2285 \mathrm{AM}^{-1} \mathrm{~cm}^{-2}$ & $79 \mathrm{nM}$ & -0.22 & [43] \\
\hline (HRP-Pd)/f-graphene-Gr & $25 \mu \mathrm{M}-3.5 \mathrm{mM}$ & 92.82 & $0.05 \mu \mathrm{M}$ & 0.02 & {$[44]$} \\
\hline $\mathrm{Pd} / \mathrm{PEDOT}$ & $2.5 \mu \mathrm{M}-1 \mathrm{mM}$ & 215.3 & $2.84 \mu \mathrm{M}$ & -0.2 & [7] \\
\hline $\mathrm{Pd} / \mathrm{MCNs} / \mathrm{GCE}$ & $7.5 \mu \mathrm{M}-10 \mathrm{mM}$ & 307.5 & $1.0 \mu \mathrm{M}$ & -0.26 & [8] \\
\hline $\mathrm{Pd} / \mathrm{CNT}$ fiber & $2 \mu \mathrm{M}-1.3 \mathrm{mM}$ & $2.75 \mathrm{AM}^{-1} \mathrm{~cm}^{-2}$ & $2 \mu \mathrm{M}$ & -0.05 & {$[6]$} \\
\hline Pd-GPE & $10 \mu \mathrm{M}-50 \mu \mathrm{M}$ & - & $1 \mu \mathrm{M}$ & -0.05 & {$[33]$} \\
\hline $\mathrm{Pd}-\mathrm{TiO}_{2}-\mathrm{GCE}$ & $10 \mu \mathrm{M}-650 \mu \mathrm{M}$ & 226.72 & $3.81 \mu \mathrm{M}$ & -0.3 & {$[45]$} \\
\hline MWCNTs-Pd/GCE & $1 \mu \mathrm{M}-10 \mathrm{mM}$ & $23.25 \mu \mathrm{AmM}^{-1}$ & $0.3 \mu \mathrm{M}$ & -0.28 & {$[46]$} \\
\hline Pd-Au nanowire array electrode & $5 \mu \mathrm{M}-2 \mathrm{mM}$ & 530 & $5 \mu \mathrm{M}$ & -0.2 & [9] \\
\hline $\mathrm{Pd} / \mathrm{CNFs}$ & $0.2 \mu \mathrm{M}-20 \mathrm{mM}$ & $4.15 \mu \mathrm{AmM}^{-1}$ & $0.2 \mu \mathrm{M}$ & -0.048 & {$[31]$} \\
\hline $\mathrm{Pd} / \mathrm{CNTs}$ & $0.1 \mu \mathrm{M}-6 \mathrm{mM}$ & - & $0.1 \mu \mathrm{M}$ & -0.2 & {$[47]$} \\
\hline Hemoglobin/Pd/graphene-chitosan & $2 \mu \mathrm{M}-1.1 \mathrm{mM}$ & $0.20 \mathrm{AM}^{-1} \mathrm{~cm}^{-2}$ & $0.66 \mu \mathrm{M}$ & -0.3 & {$[48]$} \\
\hline PB-Au(I)/AuNPs-Pd & $0.5 \mu \mathrm{M}-1 \mathrm{mM}$ & 487.1 & $0.2 \mu \mathrm{M}$ & 0.05 & {$[32]$} \\
\hline $\mathrm{Pd} /$ graphene nanosheets & $0.1 \mu \mathrm{M}-1 \mathrm{mM}$ & - & $0.05 \mu \mathrm{M}$ & -0.3 & [49] \\
\hline Pd/CILE & $5 \mu \mathrm{M}-15 \mathrm{mM}$ & 284.35 & $1 \mu \mathrm{M}$ & -0.1 & This work \\
\hline
\end{tabular}

$M C V$ mesoporous carbon vesicle, PEDOT poly(3,4ethylenedioxythiophene), MCNs mesoporous carbon nanospheres, GPE graphite pencil electrode, $C N F s$ carbon nanofibers, $C N T S$ carbon nanotubes, $P B$ Prussian blue

$0.10 \mathrm{mM}$ of $\mathrm{H}_{2} \mathrm{O}_{2}$ (twice), $5.0 \mathrm{mM}$ of glucose, $0.10 \mathrm{mM}$ of DA, $0.1 \mathrm{mM}$ of AA, $0.3 \mathrm{mM}$ of $\mathrm{UA}$, and $0.10 \mathrm{mM}$ of $\mathrm{H}_{2} \mathrm{O}_{2}$ (twice) at PdNPs/CILE are shown in Fig. 7. The current response of the PdNPs/CILE to successive injection indicates that the composite electrode has a strong and fast response to the injection of $\mathrm{H}_{2} \mathrm{O}_{2}$; however, no signal is observed with the addition of glucose, AA, DA, and UA. Thus, good selectivity was observed at the proposed electrode in

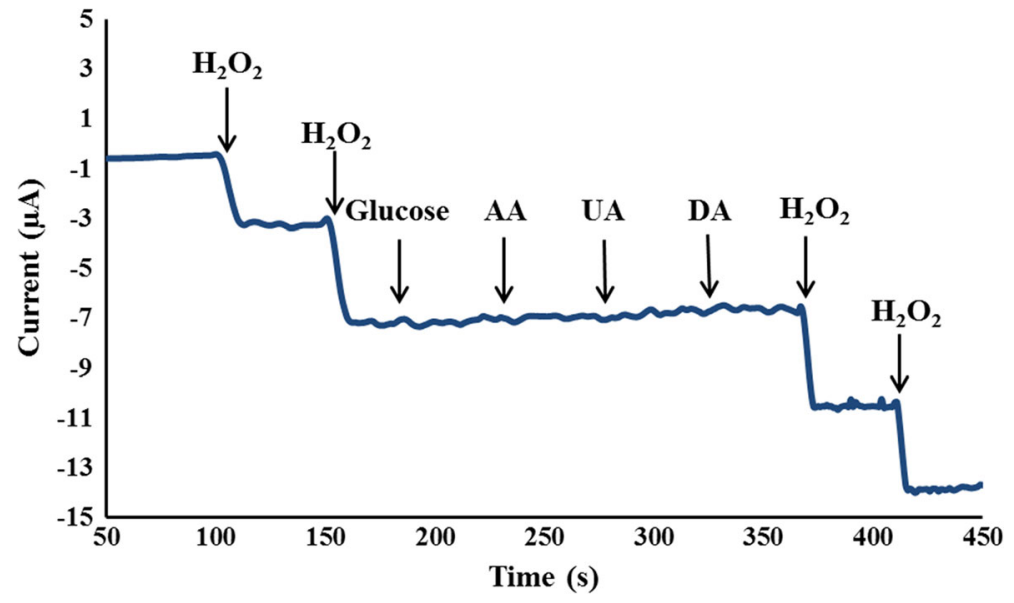

Fig. 7 Amperometric response of the PdNPs-modified CILE upon addition of $0.5 \mathrm{mM} \mathrm{H}_{2} \mathrm{O}_{2}$ (twice), $5.0 \mathrm{mM}$ glucose, $0.1 \mathrm{mM}$ ascorbic acid, $0.3 \mathrm{mM}$ uric acid, $0.1 \mathrm{mM}$ dopamine, and $1.0 \mathrm{mM} \mathrm{H}_{2} \mathrm{O}_{2}$. Applied potential $-0.2 \mathrm{~V}$ 
the presence of the most important interferences for direct electrochemical reduction of hydrogen peroxide.

\section{Conclusion}

This investigation indicates that Sargassum alga with a potential for reduction of palladium ions in particular have an immense potential for continuous production of palladium nanoparticles in a green synthesis method. Pd nanoparticles were successfully fabricated by a simple, low-cost, and ecofriendly green method using $\mathrm{PdCl}_{2}$ as a source of metal nanoparticles without any surfactants and templates. In this study, Sargassum bovinum proved to be an important biological component for biosynthesis of stable palladium nanoparticles. The catalytic performance of the biosynthetic PdNPs was investigated by electrochemical reduction of hydrogen peroxide. The PdNPs/CILE exhibited a high sensitivity and selectivity, a wide linear range, a low detection limit, and a fast response for detection of $\mathrm{H}_{2} \mathrm{O}_{2}$. The interesting performances of the electrode coupled with its simple and green preparation procedure of $\mathrm{Pd}$ synthesis make it a promising electrochemical sensing platform.

\section{References}

1. Kainz, Q. M., Linhardt, R., Grass, R. N., Vilé, G., Pérez-Ramírez, J., Stark, W. J., \& Reiser, O. (2014). Palladium nanoparticles supported on magnetic carbon-coated cobalt nanobeads: highly active and recyclable catalysts for alkene hydrogenation. Advanced Functional Materials, 24, 2020-2027.

2. Li, Y., Dai, Y., Yang, Z., \& Li, T. (2014). Controllable synthesis of palladium nanoparticles and their catalytic abilities in Heck and Suzuki reactions. Inorganica Chimica Acta, 414, 59-62.

3. Safavi, A., \& Momeni, S. (2012). Highly efficient degradation of azo dyes by palladium/hydroxyapatite/ $\mathrm{Fe}_{3} \mathrm{O}_{4}$ nanocatalyst. Journal of Hazardous Materials, 201-202, 125-131.

4. Jukk, K., Kongi, N., Matisen, L., Kallio, T., Kontturi, K., \& Tammeveski, K. (2014). Electroreduction of oxygen on palladium nanoparticles supported on nitrogen-doped graphene nanosheets. Electrochimica Acta, 137, 206-212.

5. Safavi, A., Maleki, N., Farjami, F., \& Farjami, E. (2009). Electrocatalytic oxidation of formaldehyde on palladium nanoparticles electrodeposited on carbon ionic liquid composite electrode. Journal of Electroanalytical Chemistry, 626, 75-79.

6. Liu, Y., Sun, G., Jiang, C., Zheng, X. T., Zheng, L., \& Li, C. M. (2014). Highly sensitive detection of hydrogen peroxide at a carbon nanotube fiber microelectrode coated with palladium nanoparticles. Mikrochimica Acta, 181, 63-70.

7. Jiang, F., Yue, R., Du, Y., Xu, J., \& Yang, P. (2013). A one-pot 'green' synthesis of Pd-decorated PEDOT nanospheres for nonenzymatic hydrogen peroxide sensing. Biosensors and Bioelectronics, 44, 127-131.

8. Bian, X., Guo, K., Liao, L., Xiao, J., Kong, J., Ji, C., \& Liu, B. (2012). Nanocomposites of palladium nanoparticle-loaded mesoporous carbon nanospheres for the electrochemical determination of hydrogen peroxide. Talanta, 99, 256-261.

9. Jamal, M., Hasan, M., Mathewson, A., \& Razeeb, K. M. (2012). Non-enzymatic and highly sensitive $\mathrm{H}_{2} \mathrm{O}_{2}$ sensor based on Pd nanoparticle modified gold nanowire array electrode. Journal of the Electrochemical Society, 159, B825-B829.

10. Tang, Y., Cao, Y., Wang, S., Shena, G., \& Yu, R. (2009). Surface attached-poly(acrylic acid) network as nanoreactor to in-situ synthesize palladium nanoparticles for $\mathrm{H}_{2} \mathrm{O}_{2}$ sensing. Sensors Actuat B, 137, 736-740.

11. Rastogi, P. K., Ganesan, V., \& Krishnamoorthi, S. (2014). Palladium nanoparticles decorated gaur gum based hybrid material for electrocatalytic hydrazine determination. Electrochimica Acta, 125, 593-600.

12. Shavel, A., Cadavid, D., Ibanez, M., Correte, A., \& Cabot, A. (2012). Continuous production of $\mathrm{Cu}_{2} \mathrm{ZnSnS}_{4}$ nanocrystals in a flow reactor. Journal of the American Chemical Society, 134, 1438-1441.

13. Maleki, N., Safavi, A., Farjami, E., \& Tajabadi, F. (2008). Palladium nanoparticle decorated carbon ionic liquid electrode for highly efficient electrocatalytic oxidation and determination of hydrazine. Analitica Chimica Acta, 611, 151-155. 
14. Albrecht, M. A., Evans, C. W., \& Raston, C. L. (2006). Green chemistry and the health implications of nanoparticles. Green Chemistry, 8, 417-432.

15. Kulkarni, N., Muddapur, U. (2014). Biosynthesis of metal nanoparticles: a review. Journal Nanotechnology 510246.

16. Asmathunisha, N., \& Kathiresan, K. (2013). A review on biosynthesis of nanoparticles by marine organisms. Colloids and Surfaces, B: Biointerfaces, 103, 283-287.

17. Inbakandan, D., Venkatesan, R., \& Ajmal, K. S. (2010). Biosynthesis of gold nanoparticles utilizing marine sponge Acanthella elongate (Dendy, 1905). Colloids and Surfaces, B: Biointerfaces, 81, 634-639.

18. Liu, L., Heinrich, M., Myers, S., \& Dworjanyn, S. A. (2012). Towards a better understanding of medicinal uses of the brown seaweed Sargassum in traditional Chinese medicine: a phytochemical and pharmacological review. Journal of Ethnopharmacology, 142, 591-619.

19. Yende, S., Harle, U., \& Chaugule, B. (2014). Therapeutic potential and health benefits of Sargassum species. Pharmacognosy Reviews, 8, 1-7.

20. Singaravelu, G., Arockiamary, J. S., Ganesh, K. V., \& Govindaraju, K. (2007). A novel extracellular synthesis of monodisperse gold nanoparticles using marine alga Sargassum wightii Greville. Colloids and Surfaces. B: Biointerfaces, 57, 97-101.

21. Mata, Y. N., Torres, E., Blázquez, M. L., Ballester, A., González, F., \& Mũnoz, J. A. (2009). Gold(III) biosorption and bioreduction with the brown alga fucus vesiculosus. Journal of Hazardous Materials, 166, $612-618$

22. Ramakritinan, C. M., Kaarunya, E., Shankar, S., \& Kumaraguru, A. K. (2013). Antibacterial effects of Ag, $\mathrm{Au}$ and bimetallic (Ag-Au) nanoparticles synthesized from red algae. Solid State Phenomena, 201, 211-230.

23. Vivek, M., Kumar, P. S., Steffi, S., \& Sudha, S. (2011). Biogenic silver nanoparticles by Gelidiella acerosa extract and their antifungal effects. Avicenna Journal of Medical Biotechnology, 3, 143-148.

24. Schröfel, A., Kratošová, G., Bohunická, M., Dobročka, E., \& Vávra, I. (2011). Biosynthesis of gold nanoparticles using diatoms-silica gold and EPS-gold bio nanocomposite formation. Journal of Nanoparticle Research, 13, 3207-3216.

25. Yang, X., Li, Q., Wang, H., Huang, J., Lin, L., Wang, W., Sun, D., Su, Y., Opiyo, J. B., Hong, L., Wang, Y., He, N., \& Jia, L. (2010). Green synthesis of palladium nanoparticles using broth of Cinnamomum camphora leaf. Journal of Nanoparticle Research, 12, 1589-1598.

26. Sathishkumar, M., Sneha, K., Kwak, I. S., Mao, J., Tripathy, S. J., \& Yun, Y.-S. (2009). Phyto-crystallization of palladium through reduction process using Cinnamomum zeylanicum bark extract. Journal of Hazardous Materials, 171, 400-404.

27. Jia, L., Zhang, Q., Li, Q., \& Song, H. (2009). The biosynthesis of palladium nanoparticles by antioxidants in Gardenia jasminoides Ellis: long lifetime nanocatalysts for p-nitrotoluene hydrogenation. Nanotechnology, 20,385601 .

28. Kriz, K., Anderlund, M., \& Kriz, D. (2001). Real-time detection of L-ascorbic acid and hydrogen peroxide in crude food samples employing a reversed sequential differential measuring technique of the SIRE technology based biosensor. Biosensors and Bioelectronics, 16, 363-369.

29. Wang, J. (2008). Electrochemical glucose biosensors. Chemical Reviews, 108, 814-825.

30. Safavi, A., Maleki, N., \& Farjami, E. (2009). Electrodeposited silver nanoparticles on carbon ionic liquid electrode for electrocatalytic sensing of hydrogen peroxide. Electroanalysis, 21, 1533-1538.

31. Huang, J., Wang, D., Hou, H., \& You, T. (2008). Electrospun palladium nanoparticle-loaded carbon nanofibers and their electrocatalytic activities towards hydrogen peroxide and NADH. Advanced Functional Materials, 18, 441-448.

32. Pandey, P. C., \& Pandey, A. K. (2012). Surface modification using Prussian blue-gold (I)-palladium nanocomposite: towards bioelectrocatalytic probing of hydrogen peroxide. BioNanoScience, 2, 127-134.

33. Aziz, M. A., \& Kawde, A.-N. (2013). Nanomolar amperometric sensing of hydrogen peroxide using a graphite pencil electrode modified with palladium nanoparticles. Mikrochimica Acta, 180, 837-843.

34. Li, M., Xu, S., Tang, M., Liu, L., Gao, F., \& Wang, Y. (2011). Direct electrochemistry of horseradish peroxidase on graphene-modified electrode for electrocatalytic reduction towards $\mathrm{H} 2 \mathrm{O} 2$. Electrochimica Acta, 56, 1144-1149.

35. Liu, H., Duan, C., Su, X., Dong, X., Huang, Z., Shen, W., \& Zhu, Z. (2014). A hemoglobin encapsulated titania nanosheet modified reduced graphene oxide nanocomposite as a mediator-free biosensor. Sensors and Actuators B: Chemical, 203, 303-310.

36. Safavi, A., \& Farjami, F. (2010). Hydrogen peroxide biosensor based on a myoglobin/hydrophilic room temperature ionic liquid film. Analytical Biochemistry, 402, 20-25.

37. Yang, F., Cheng, K., Wu, T., Zhang, Y., Yin, J., Wang, G., \& Cao, D. (2013). Au-Pd nanoparticles supported on carbon fiber cloth as the electrocatalyst for $\mathrm{H} 2 \mathrm{O} 2$ electroreduction in acid medium. Journal of Power Sources, 233, 252-258. 
38. Maleki, N., Safavi, A., \& Tajabadi, F. (2006). High-performance carbon composite electrode based on an ionic liquid as a binder. Analytical Chemistry, 78, 3820-3826.

39. Safavi, A., Momeni, S., \& Tohidi, M. (2012). Silver-palladium nanoalloys modified carbon ionic liquid electrode with enhanced electrocatalytic activity towards formaldehyde oxidation. Electroanalysis, 24, 19811988.

40. Yonezawa, T., Imamura, K., \& Kimizuka, N. (2001). Direct preparation and size control of palladium nanoparticle hydrosols by water-soluble isocyanide ligands. Langmuir, 17, 4701-4703.

41. Zhang, X., Yin, H., Wang, J., Chang, L., Gao, Y., Liu, W., \& Tang, Z. (2013). Shape-dependent electrocatalytic activity of monodispersed palladium nanocrystals toward formic acid oxidation. Nanoscale, 5, 83928397.

42. Shao, P., Chen, X., \& Sun, P. (2014). Chemical characterization, antioxidant and antitumor activity of sulfated polysaccharide from Sargassum horneri. Carbohydrate Polymers, 105, 260-269.

43. Bo, X., Bai, J., Ju, J., \& Guo, L. (2010). A sensitive amperometric sensor for hydrazine and hydrogen peroxide based on palladium nanoparticles/onion-like mesoporous carbon vesicle. Analitica Chimica Acta, $675,29-35$.

44. Nandini, S., Nalini, S., Manjunatha, R., Shanmugam, S., Melo, J. S., \& Suresh, G. S. (2013). Electrochemical biosensor for the selective determination of hydrogen peroxide based on the codeposition of palladium, horseradish peroxidase on functionalized-graphene modified graphite electrode as composite. Journal of Electroanalytical Chemistry, 689, 233-242.

45. Kong, L., Lu, X., Bian, X., Zhang, W., \& Wang, C. (2010). A one-pot synthetic approach to prepare palladium nanoparticles embedded hierarchically porous $\mathrm{TiO} 2$ hollow spheres for hydrogen peroxide sensing. Journal of Solid State Chemistry, 183, 2421-2425.

46. You, J.-M., Jeong, Y. N., Ahmed, M. S., Kim, S. K., Choi, H. C., \& Jeon, S. (2011). Reductive determination of hydrogen peroxide with MWCNTs-Pd nanoparticles on a modified glassy carbon electrode. Biosensors and Bioelectronics, 26, 2287-2291.

47. Zhang, W.-J., Bai, L., Lu, L.-M., \& Chen, Z. (2012). A novel and simple approach for synthesis of palladium nanoparticles on carbon nanotubes for sensitive hydrogen peroxide detection. Colloids and Surfaces, B: Biointerfaces, 97, 145-149.

48. Sun, A., Sheng, Q., \& Zheng, J. (2012). A hydrogen peroxide biosensor based on direct electrochemistry of hemoglobin in palladium nanoparticles/graphene-chitosan nanocomposite film. Applied Biochemistry and Biotechnology, 166, 764-773.

49. Chen, X.-M., Cai, Z.-X., Huang, Z.-Y., Oyama, M., Jiang, Y.-Q., \& Chen, X. (2013). Ultrafine palladium nanoparticles grown on graphene nanosheets for enhanced electrochemical sensing of hydrogen peroxide. Electrochimica Acta, 97, 398-403. 